\title{
III Encontro Internacional de História sobre as Operações Bélicas da
Guerra da Triplice Aliança
}

Referencial Histórico*

\section{Invasão}

Em meados de dezembro de 1864, tropa paraguaia, comandada por Vicente Barrios, subiu o rio Paraguai e tomou o Forte de Coimbra, as povoações de Albuquerque e Corumbá. Outra tropa, comandada por Isidoro Resquin, por terra, destruiu a Colônia Militar do Miranda, as povoações de Nioaque e Miranda. Um destacamento, comandado por Urbieta, destruiu a Colônia Militar do Dourados. Outro destacamento, comandado por Aguero, partindo de Miranda, incendiou o Núcleo Colonial do Taquari (hoje Coxim).

\section{Reação}

Declarada a guerra, decidiu o Império brasileiro atacar a República do Paraguai com a Coluna Sul, por Corrientes, até Assunção; e com a Norte, por Miranda e Apa, atingindo Conceição e, daí, até a capital. A Coluna Sul foi formada principalmente por soldados que já se encontravam no sul do Brasil, mais argentinos e uruguaios. Esta Coluna entrou no território paraguaio em 16 de abril de

\footnotetext{
* O material aqui apresentado foi organizado por Hildebrando Campestrini, publicado em forma de folheto, e distribuído aos particicipantes do Encontro.
} 


\section{CRONOLOGIA DA GUERRA DA TRÍPLICE ALIANÇA}

\begin{tabular}{|c|c|c|c|}
\hline Ano & Dia-mês & Frente Sul & Frente Norte \\
\hline 1864 & $13 \mathrm{dez}$. & \multicolumn{2}{|c|}{ O Paraguai declara guerra ao Império do Brasil. } \\
\hline & 14 dez. & & $\begin{array}{l}\text { Partem de Conceição } \\
\text { os invasores. }\end{array}$ \\
\hline & 29 dez. & & $\begin{array}{l}\text { Os brasileiros abandonam o } \\
\text { Forte de Coimbra. Morre, na } \\
\text { Colônia do Dourados, o } \\
\text { tenente Antônio João Ribeiro. }\end{array}$ \\
\hline 1865 & 1. jan. & & $\begin{array}{l}\text { Os invasores entram em } \\
\text { Albuquerque. }\end{array}$ \\
\hline & 2 jan. & & $\begin{array}{l}\text { Resquin toma Nioaque. Dias } \\
\text { depois a vila de Miranda. }\end{array}$ \\
\hline & 4 jan. & & $\begin{array}{l}\text { Os paraguaios tomam } \\
\text { Corumbá. }\end{array}$ \\
\hline & 7 jan. & \multicolumn{2}{|c|}{ Criação dos "Voluntários da Pátria", pelo Imperador. } \\
\hline & 20 fev. & $\begin{array}{l}\text { Rendição de Montevidéu. O } \\
\text { Uruguai se alia ao Brasil. }\end{array}$ & \\
\hline & 10 abr. & & $\begin{array}{l}\text { A Força Exp. deixa São Paulo } \\
\text { rumo a Campinas. }\end{array}$ \\
\hline & $15 \mathrm{abr}$. & & A Força chega a Campinas. \\
\hline & 24 abr. & $\begin{array}{l}\text { O capitão Aguero chega ao } \\
\text { Núcleo Colonial do Taquari. }\end{array}$ & \\
\hline & $1 .^{\circ}$ maio & Tratado da Tríplice Aliança. & \\
\hline & 11 junho & $\begin{array}{l}\text { Batalha de Riachuelo. } \\
\text { Estigarribia toma São Borja. }\end{array}$ & \\
\hline & 20 junho & & A Força deixa Campinas. \\
\hline & 18 julho & & $\begin{array}{l}\text { A Força chega a Uberaba, } \\
\text { incorporando a brigada } \\
\text { mineira. }\end{array}$ \\
\hline & 4 set. & & A Força deixa Uberaba. \\
\hline & 18 set. & $\begin{array}{l}\text { Capitulação de Estigarribia } \\
\text { em Uruguaiana. }\end{array}$ & \\
\hline & $20 \mathrm{dez}$. & & A Força chega a Coxim. \\
\hline 1866 & 16 abril & $\begin{array}{l}\text { Os aliados invadem o } \\
\text { Paraguai, pelo Passo da Pátria. }\end{array}$ & \\
\hline & 25 abril & & Parte de Coxim a $1 .^{a}$ brigada. \\
\hline & 8 maio & & $\begin{array}{l}\text { A } 1 .{ }^{\text {a }} \text { brigada chega ao rio } \\
\text { Negro. }\end{array}$ \\
\hline & 24 maio & Batalha de Tuiuti. & \\
\hline & 4 junho & & $\begin{array}{l}\text { A 2." brigada chega ao rio } \\
\text { Negro. }\end{array}$ \\
\hline & 24 junho & & A Força parte para o Taboco. \\
\hline
\end{tabular}




\begin{tabular}{|c|c|c|c|}
\hline & 3 set. & $\begin{array}{l}\text { Os aliados tomam a fortaleza } \\
\text { de Curuzu. }\end{array}$ & \\
\hline & 5 set. & & $\begin{array}{l}\text { A Força parte do Taboco para } \\
\text { Miranda. }\end{array}$ \\
\hline & 10 set. & $\begin{array}{l}\text { Caxias assume o comando do } \\
\text { Exército brasileiro. }\end{array}$ & \\
\hline & 17 set. & & A Força chega a Miranda. \\
\hline & 22 set. & $\begin{array}{l}\text { Derrota dos aliados em } \\
\text { Curupaiti. }\end{array}$ & \\
\hline \multirow[t]{15}{*}{1867} & 11 jan. & & A Força parte para Nioaque. \\
\hline & 24 jan. & & A Força chega a Nioaque. \\
\hline & & & $\begin{array}{l}\text { A Força movimenta-se em } \\
\text { direção ao rio Apa. }\end{array}$ \\
\hline & 21 abril & & A Força atravessa o rio Apa. \\
\hline & 5 maio & & A Força ataca Laguna. \\
\hline & 8 maio & & A Força inicia a retirada. \\
\hline & 11 maio & & $\begin{array}{l}\text { A Força atravessa o rio Apa. } \\
\text { Combate de Nhandipá. }\end{array}$ \\
\hline & 25 maio & & $\begin{array}{l}\text { A Força abandona os colé- } \\
\text { ricos no Cambaracê. }\end{array}$ \\
\hline & 4 junho & & A Força chega a Nioaque. \\
\hline & 11 junho & & A Força chega ao Canuto. \\
\hline & 13 junho & & Retomada de Corumbá. \\
\hline & 2 agosto & Começa o cerco a Humaitá. & \\
\hline & 15 agosto & Tomada de Curupaiti. & \\
\hline & 26 agosto & & A Força parte para Cuiabá. \\
\hline & 19 out. & & A Força chega a Cuiabá. \\
\hline \multirow[t]{6}{*}{1868} & 3 jan. & $\begin{array}{l}\text { Caxias assume o comando } \\
\text { das tropas aliadas. }\end{array}$ & \\
\hline & 25 julho & $\begin{array}{l}\text { Os aliados entram na } \\
\text { fortaleza de Humaitá. }\end{array}$ & \\
\hline & 6 dez. & Os aliados tomam Itororó. & \\
\hline & 11 dez. & Batalha de Avaí. & \\
\hline & 21-27 dez. & Batalha de Lomas Valentinas. & \\
\hline & 30 dez. & Queda de Angustura. & \\
\hline \multirow[t]{3}{*}{1869} & 1. jan. & Os aliados tomam Assunção. & \\
\hline & 12 agosto & Batalha de Peribebui. & \\
\hline & 16 agosto & Batalha de Nhuguaçu. & \\
\hline \multirow[t]{3}{*}{1870} & 29 jan. & Lopez acampa em Capivari. & \\
\hline & 14 fev. & Lopez chega a Cerro Corá. & \\
\hline & $10^{\circ}$ março & Lopez é morto em Cerro Corá. & \\
\hline
\end{tabular}


1866. Para compor a Coluna Norte, no início de 1865, organizou-se uma tropa, principalmente de voluntários, reunindo forças de linha estacionadas no Paraná, em São Paulo, Minas Gerais e Goiás. Estas forças, concentradas em Uberaba, formavam a Força Expedicionária de Mato Grosso.

\section{A Força Expedicionária de Mato Grosso}

Reuniram-se as forças em Uberaba: eram duas brigadas, somando 2.600 homens: a mineira (com 1.200 homens) e a paulista - que seriam acrescidas por soldados goianos de linha e voluntários (incluído um esquadrão de cavalaria), concentrados em Uberaba (MG), formando a Força Expedicionária de Mato Grosso. Partindo de Uberaba a 4 de setembro de 1865, a Força Expedicionária rumou para Cuiabá mas, à altura do rio dos Bois (GO), regressando o coronel Drago (seu comandante) para a corte, tomou a direção de Coxim, por determinação superior. A Força chegou a Coxim em meados de dezembro (de 1865), onde estacionou. Daí partiu (para Miranda), em 25 de abril de 1866, a primeira brigada, que acampou no Potreiro, perto do rio Negro, no dia 8 de maio; depois movimentou-se a outra brigada, que chegou àquele pouso a 4 de junho; reunidas junto ao rio, foram inesperadamente cercadas pela inundação do Pantanal. Ilhada, sem alimentos e sem poder locomover-se, a Força foi tomada pela fome, malária e beribéri, ocorrendo numerosos óbitos, entre eles o do próprio comandante, coronel Galvão.

No dia 24 de junho pôde a Força deslocar-se em direção à fazenda Taboco, atingindo-a no dia 3 de julho - homens quase nus, esquálidos, devorados de fome, no último estado de desalento e miséria, verdadeira tropa de bandidos maltrapilhos (Taunay, MEMóRIAs, p. 212).

Taunay ${ }^{1}$ registra que, na travessia de Coxim ao Taboco, sem exageração, haviam morrido em menos de seis meses mais de 2.000 praças, sendo pequeno o desfalque por deserção. (....). Calcule-se o que não ficou enterrado no lodo, de gente, da bagagem e comitiva!

${ }^{1}$ TAUNAY, Visconde de. Em Matto Grosso invadido (1866 - 1867). São Paulo: Melhoramentos, s/d. 
A 5 de setembro a Força marchou para Miranda; desfalcada de centenas de soldados, sem cavalos, com os canhões intactos (só quatro, oito haviam ficado no Núcleo Colonial do Taquari ${ }^{\mathbf{1 7 4}}$ ); acampou às margens do córrego da Piranhinha; no dia seguinte chegou ao porto Sousa, cuja travessia durou do dia 7 ao 13; a 14, retomou a marcha, chegando à vazante do Ipegue. No dia seguinte chegou ao Naxedaxe, no dia 16 marchou até o córrego Agachi, onde acampou; no dia 17 de setembro, partiu para Miranda; uma hora da tarde, a tropa acampou na vila, já saqueada e incendiada, em ruínas: ardera parte das construções (....); ainda se mantinham de pé prédios cômodos (Taunay) e o quartel estava muito deteriorado pelo fogo. Miranda era foco de infecção palustre e o beribéri continuava a ceifar vidas, entre elas a do padre Molina.

A $1 .^{\circ}$ de janeiro de 1867, o coronel Camisão, vindo de Cuiabá, assumiu o comando da Força. A 11 de janeiro de 1867 a Força partiu para Nioaque com menos de 2.000 homens; marchando por campos limpos, passando pelo Lauiad (campo belo, alegre) e, quatro léguas adiante, pela Forquilha (confluência dos rios Nioaque e Miranda) e depois pelos córregos Areias e Formiga, chegou a 24 àquela vila, já incendiada e saqueada pelos paraguaios, onde permaneciam de pé apenas duas casas e a igreja, cuja nave serviu de depósito ao cartuchame e a todas as munições (RETIRADA, p. 40.

Aí se apresentou o voluntário José Francisco Lopes, que conhecia muito bem os campos do Apa. O coronel Camisão resolveu avançar e a 25 de fevereiro fez sua tropa levantar acampamento, estacionando, porém, a uma légua da vila. Dias depois, o coronel resolveu partir para a Colônia Militar do Miranda (80 $\mathrm{km}$ de Nioaque, já destruída pelos paraguaios), onde chegou a 4 de março, depois de transpor, no dia 26 (de fevereiro), os rios Canindé; no dia 27, o Desbarrancado; em 2 de março, o Feio.

No dia 15 de abril, a tropa marchar para o rio Apa; de 16 para 17, pernoitou no Retiro (perto da fazenda do falecido Gabriel Francisco Lopes); a 19, atravessou o Taquaruçu, acampando às margens do córrego Sombrero; no dia seguinte, tomou a fazenda Machorra, guarnecida por poucos paraguaios; a 21, atravessou o Apa, com 1.680 soldados (Taunay, p. 167). Camisão intimou a se render a pequena tropa paraguaia que guarnecia o Forte de Bella Vista, proposta naturalmente de imediato rechaçada. No dia 30, a coluna avançou até o Apami, 
uma légua adiante. No dia seguinte (1. ${ }^{\circ}$ de maio), acampou perto da fazenda Laguna.

No dia 5 de maio, Camisão ordenou que o $1 .{ }^{\circ}$ Corpo de Caçadores (a pé), sob o comando do capitão Pedro José Rufino, e o 21. ${ }^{\circ}$ de Infantaria, sob o comando do major José Tomás Gonçalves, somando 527 homens e trinta índios, sem canhões e sem cavalaria, tomassem o acampamento paraguaio de Laguna. Não conseguiu, embora os paraguaios debandassem.

Faltavam víveres e munição; impunha-se a retirada. Enquanto os brasileiros levantavam o acampamento ( 8 de maio), à saída, os paraguaios atacaram. No dia 9, os brasileiros marcharam, sob o fogo de guerrilhas, para acampar, à tarde, em elevação sobre o rio Apa e o antigo forte paraguaio, onde estacionaram dois dias. No dia 10, a tropa falhou, para descanso.

A 11, avançava a tropa em quadrado, com um canhão em cada ângulo, após atravessar o Apa (levara nisto mais de quatro horas), quando surgiram (às 11 horas) os paraguaios, atacando vigorosamente para romper o quadrado; reagindo, os de Camisão, de arma branca em punho, expulsaram os invasores. Cavalarianos inimigos, renteando o quadrado, capturaram o gado alvoroçado. $\mathrm{O}$ combate, acérrimo, conhecido como de Nhandipá, deixou, segundo Taunay (p. 99), 230 mortos, numa luta entre duas colunas, cujo total, quando muito, atingia 3.000 homens.

No dia 11 de maio, infletiram os retirantes para o oeste. No dia 12, a coluna transpuseram o córrego José Carlos, rumo norte, estacionando pouco adiante. A marcha foi retomada no dia 14 . No dia 16 a coluna atravessou o ribeirão das Cruzes (hoje Piripucu). Dia 18 choveu muito. Não bastasse a fome, apareceram, nesse dia, com mais frequência, casos de cólera. A 19, atravessou um córrego formado pela chuva.

No dia 20 o tempo melhorou; neste dia fez a cólera nove vítimas e surgiram mais vinte casos e, como registrou Tomás Gonçalves, o fogo inimigo durou desde a manhã até as quatro horas da tarde. A 21, a coluna continuou a marcha, passou pelo Campo das Cruzes (com o morro da Margarida ao fundo). A 22, andou uns cinco quilômetros, já perto do Prata (o atual rio Verde); a 25 (após um dia de intensa chuva), avançou cerca de légua e meia, até aquele rio, em cuja transposição já eram, segundo Taunay, noventa e seis as padiolas com doentes. 
$\mathrm{Na}$ noite do dia 25, Camisão, sob a própria responsabilidade (Taunay, $\mathrm{p}$. 134), resolveu abandonar, na madrugada seguinte, os moribundos numa clareira à margem do Cambaracê - eram uns cem coléricos (entre eles 76 soldados, sobrevivendo um), passados pelas armas paraguaias. No dia 26 morria o filho de Lopes (sepultado à margem direita do Miranda, em terras do pai) e o tenente-coronel Juvêncio caía doente; a coluna, depois de percorrer três léguas e meia, acampou no retiro da fazenda de Lopes, que, assaltado pela cólera, caiu do cavalo; Camisão também manifestou-a.

No dia seguinte, o inimigo se aproximou da coluna, que avançou até alcançar, meia légua adiante, o rio Miranda, avolumado pelas chuvas. Morreu Lopes e aí foi enterrado. No dia 28, o Corpo de Caçadores atravessou o rio. No dia 29 faleceu, de manhã, Camisão; à tarde, o tenente-coronel Juvêncio, enterrados à margem do Miranda. No local foi construído, por ordem do Imperador, um cemitério, hoje Cemitério dos Heróis, cujos restos foram transladados, décadas depois, transladados para o monumento aos Heróis da Retirada da Laguna e Dourados, no Rio de Janeiro. No mesmo dia 29, assumiu o comando o major José Tomás Gonçalves, que determinou a travessia do rio.

A primeiro de junho, registra Taunay, à tarde, achamo-nos todos, afinal, reunidos em torno da casa de Lopes, no seu pomar, por nós despojado dos frutos, e logo, sem mais repouso ou alimento, recomeçamos a caminhar rumo a Nioaque.

A coluna partiu, naquele dia, às seis da tarde e, caminhando sob intensa chuva, a noite inteira, agora por caminhos conhecidos, chegou às três horas do dia seguinte à margem do Canindé, onde estavam à mostra os destroços do saque às carretas dos comerciantes, estando o chão coberto de farinha e arroz. A soldadesca comeu, enfim, apanhando tudo que foi encontrado, depois de vinte e dois dias de cruel fome (J. Tomás Gonçalves). E no dia 4, entrou em Nioaque, já arrasada, só com sua pequena igreja de pé. Nela os paraguaios deixaram armada uma cilada: um barril de pólvora para explodir ao ser acionado um isqueiro de pedra, colocado de propósito. A explosão feriu treze soldados, dos quais seis faleceram.

No dia 5, a Coluna deixou Nioaque, seguindo a estrada do Aquidauana; a 6, pernoitou no ribeirão das Areias; a 8, acampou à margem do Taquaruçu, 
que estava transbordante; nesse dia, teve o último contato com a tropa paraguaia, que retornou para o Apa; a 9, atravessado o rio, livrou-se da fome (suprida pelo serviço de intendência, que veio a seu encontro); a 10, atravessou o Dois Córregos; a 11, chegou ao porto do Canuto: dos 2.600 homens (os números não são unânimes) que partiram de Coxim, só 2.200 chegaram a Miranda; menos de 2.000 partiram para Nioaque; deles, só 1.680 penetraram no Paraguai; e 700 chegaram ao Canuto.

No dia 19, o major Tomás Gonçalves fez seus soldados acamparem junto ao córrego Correntes (perto de Palmeiras hoje); a 17, por ordem do comandante, viajou para a corte o secretário do comando, o tenente-engenheiro Alfredo Taunay, a fim de entregar o relatório da expedição ao gabinete imperial.

Recebeu, afinal, o comandante, em 30 de julho, ordens para tomar o rumo de Cuiabá. A 26 de agosto partiram os sobreviventes da Força para a capital da província. Pela mesma rota da Força Expedicionária, vararam o Aquidauana, o Negro e o Taquari; continuando pela estrada do Piquiri chegaram a Cuiabá, em 19 de outubro. E de lá, meses depois, uns tantos deles partiram para a campanha na República do Paraguai. 


\section{ROTEIRO DAS FORÇAS PARAGUAIAS}

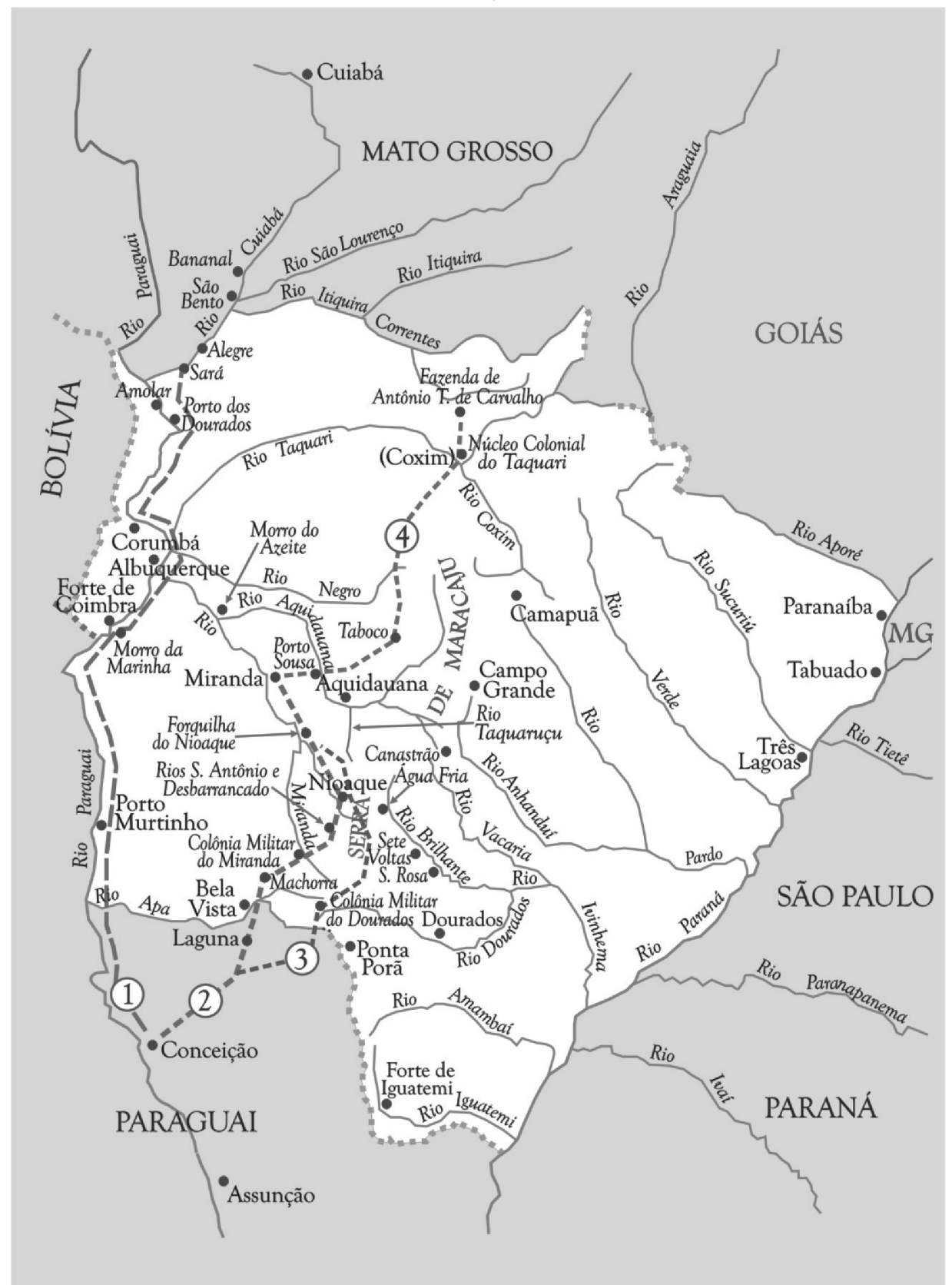

Rota das tropas paraguaias: 1. Vicente Barrios (por água). 2. Coluna Resquin (até Miranda). 3 Coluna Urbieta. 4. Coluna Aguero (Miranda-Coxim). 


\section{ROTEIRO DA FORÇA EXPEDICIONÁRIA DE MATO GROSSO DE UBERABA E LAGUNA}

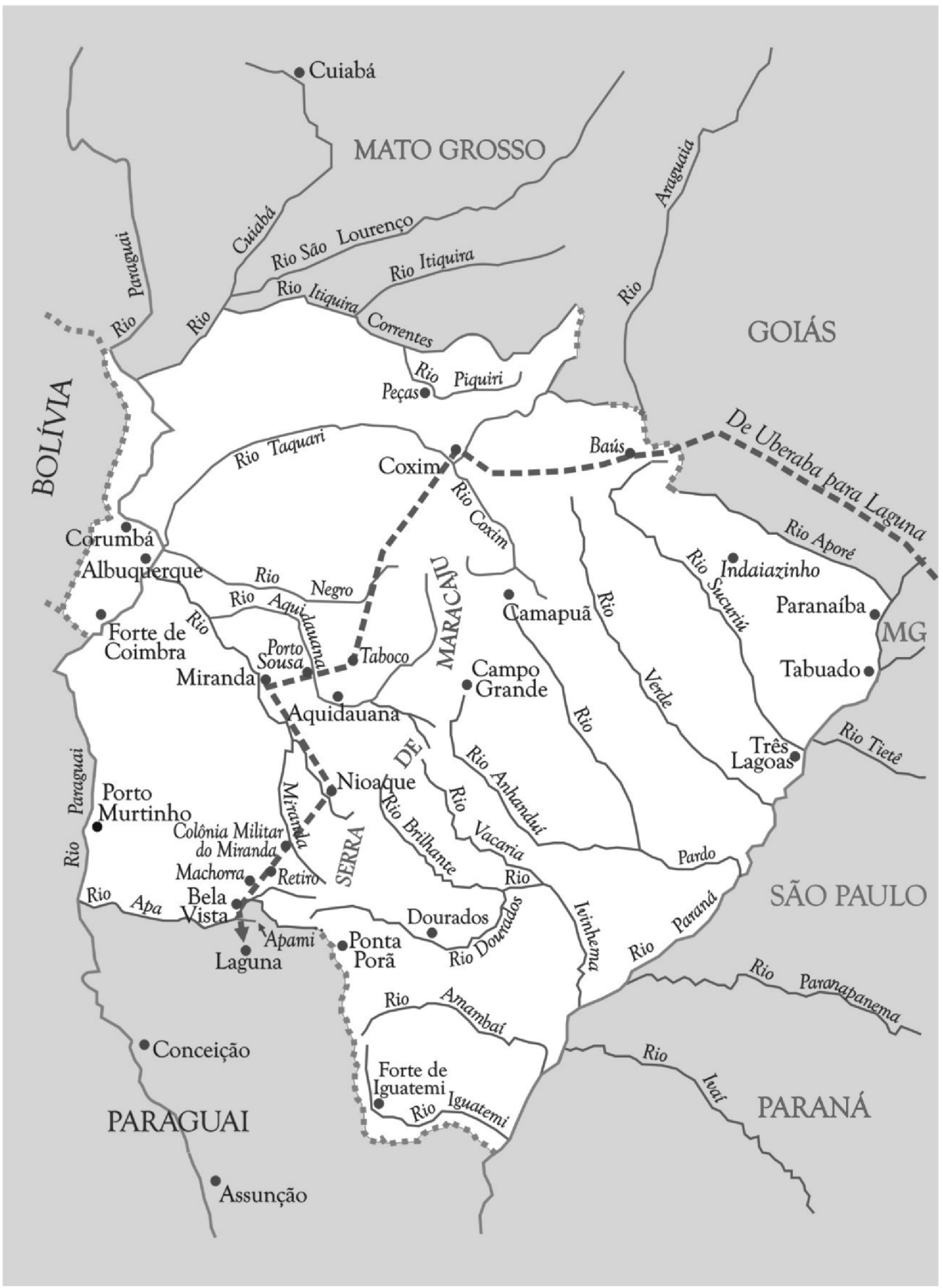




\section{ROTEIRO DA FORÇA EXPEDICIONÁRIA DE MATO GROSSO:}

MIRANDA - LAGUNA - PORTO CANUTO

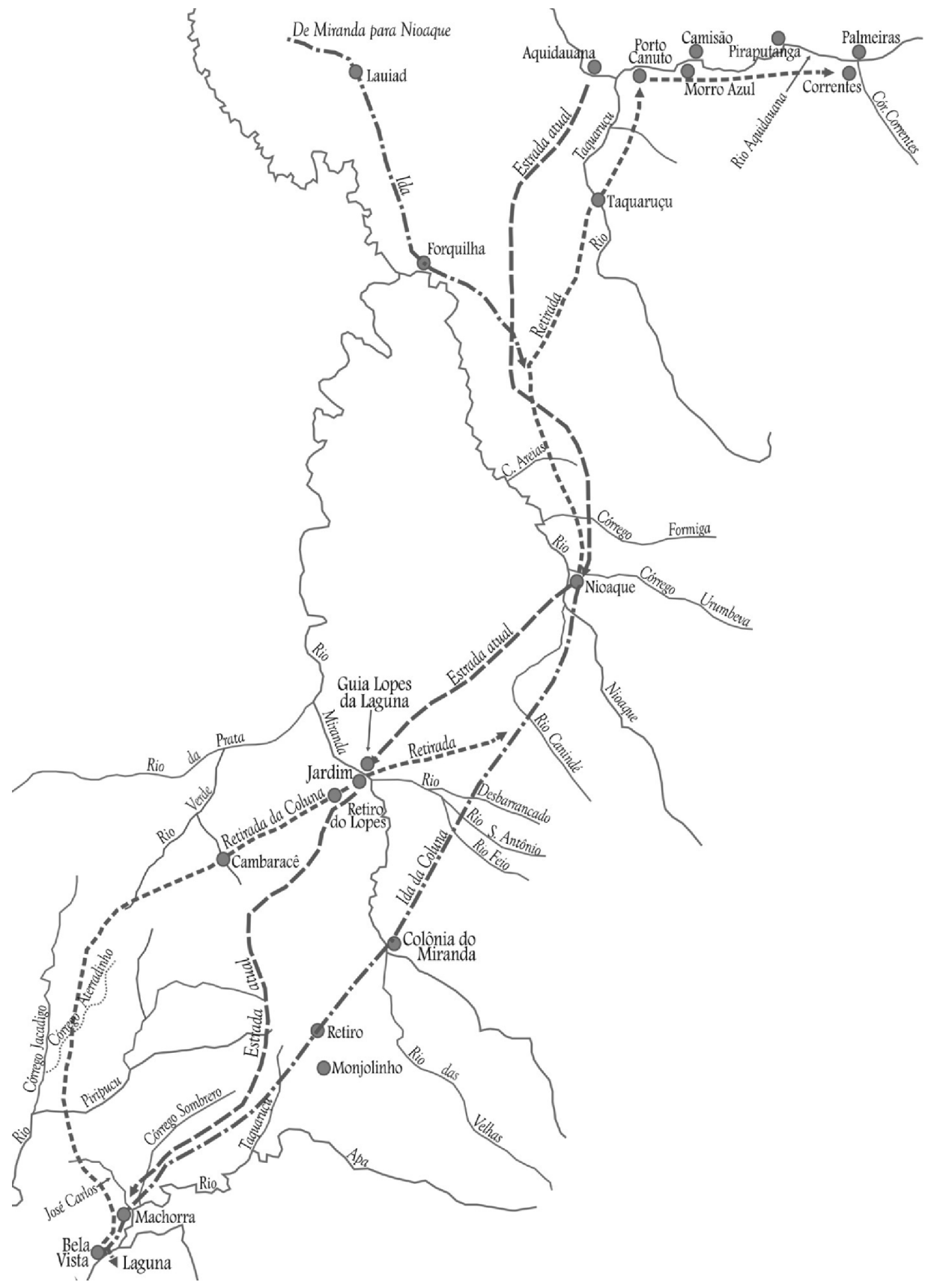

